\title{
Growth and Differentiation of Human Dental Pulp Stem Cells Maintained in Fetal Bovine Serum, Human Serum and Serum-free/Xeno-free Culture Media
}

Rashi Khanna-Jain ${ }^{1,2,3 *}$, Sari Vanhatupa ${ }^{1,2,3}$, Annukka Vuorinen ${ }^{1,2,3,4}$, George K.B. Sandor ${ }^{1,2,3,7}$, Riitta Suuronen ${ }^{1,2,3,4,5,6}$, Bettina Mannerstrom ${ }^{1,2,3}$ and Susanna Miettinen ${ }^{1,2,3}$

${ }^{1}$ Adult Stem Cells, Institute of Biomedical Technology, University of Tampere, Finland

${ }^{2}$ BioMediTech, Tampere, Finland

${ }^{3}$ Science centre, Tampere University Hospital, Tampere, Finland

${ }^{4}$ Finnish Student Health Service, Tampere, Finland

${ }^{5}$ Department of Eye, Ear and Oral Diseases, Tampere University Hospital, Finland

${ }^{6}$ Department of Biomedical Engineering, Tampere University of Technology, Finland

${ }^{7}$ Oral and Maxillofacial Surgery, University of Oulu, Oulu, Finland

\begin{abstract}
Introduction: Dental pulp stem cells (DPSCs) are an accessible cell source with therapeutic applicability in regeneration of damaged tissues. Current techniques for expansion of DPSCs require the use of Fetal Bovine Serum (FBS). However, animal-derived reagents stage safety issues in clinical therapy. By expanding DPSCs in serumfree/ xenofree medium (SF/XF-M) or in medium containing human serum (HS-M), the problems can be eliminated. Therefore, the aim of our study was to identify suitable cell culture media alternatives for DPSCs.

Methods: We studied the isolation, proliferation, morphology, cell surface markers (CD29, CD44, CD90, CD105, CD31, CD45 and CD146), stemness markers expression (Oct3/4, Sox2, Nanog and SSEA-4) and in vitro multilineage differentiation of DPSCs in HS-M or SF/XF-M in comparison to FBS-M.

Results: DPSCs expressed the cell surface and stemness markers in all studied conditions. The proliferation analysis of cells cultured in different HS concentrations revealed that cells isolated in $20 \%$ HS-M and passaged in $10 \%$ or $15 \%$ HS-M supported the cell growth. Direct isolation of cells in SF/XF-M did not support cell proliferation. Therefore, cells cultured in $20 \%$ HS-M were used for further SF/XF-M studies. However, proliferation of DPSCs was significantly lower in SF/XF-M when compared with cells cultured in FBS-M and HS-M. In addition, proliferation of DPSCs in SF/XF-M could be enhanced by addition of $1 \% \mathrm{HS}$ in cell culture medium. There were differences in osteogenic, chondrogenic and adipogenic differentiation efficacy between cells cultured in FBS, HS and SF/XF differentation media. More pronounced adipogenic and osteogenic differentiation was observed in HS differentiation medium, however, in FBS-M cultured cells more effective chondrogenic differentiation was detected.
\end{abstract}

Conclusions: Our results indicate that HS is a suitable alternative to FBS for the expansion of DPSCs. The composition of SF/XF-M needs to be further optimized in terms of cell expandability and differentiation efficiency to reach clinical applicability.

Keywords: Dental pulp stem cells (DPSCs); Human serum (HS); Serumfree/xenofree (SF/XF); Cell isolation; Expansion and differentiation

\section{Introduction}

Adult mesenchymal stem cells (MSCs) isolated from bone marrow (BM) have been an important source of stem cells for stem cell based therapies for the past several years [1,2]. Besides their regenerative capacity, there are certain limitations associated with BM-MSCs such as tissue site morbidity, low cell numbers and painful procedure for procuring the tissue $[3,4]$; therefore, several alternative sources of MSCs have been sought. MSCs have been expanded from adipose tissue [5], skeletal muscle [6], umbilical cord [7], amniotic fluid [8], dental pulp tissue [9] and numerous other tissues [10].

Dental pulp stem cells (DPSCs) have been reported to exhibit multipotent differentiation capacity into various cell lineages such as adipocytes, osteocytes, chondrocytes, and myocytes in vitro [11]; including in vivo studies showing differentiation of DPSCs into odontoblasts [12], neural cells [13], and in cardiac repair by improving angiogenesis [14]. Moreover, there are several animal studies reporting the potential of DPSCs in regenerating bone $[15,16,17]$ and one clinical study showing the successful use of DPSCs in bone augmentation in tooth extraction sockets [18]. Apart from their osteogenic regenerative potential, it has been reported that DPSCs display increased immunosuppressive activity when compared with BM-MSCs [19]. Because of the multipotent nature and immunomodulatory properties of DPSCs [20], they may be an important source of MSCs for stem cell based therapies.

Furthermore, for cell based therapies, experimental concerns caused due to current cell culture protocols comprising of animal derived components needs to be eliminated. There are several

*Corresponding author: Rashi Khanna-Jain, Adult Stem Cells, Institute of Biomedical Technology, University of Tampere, Biokatu-12, 33520 Tampere, Finland, Tel: +358-4-1901789; Fax: +358-3-35518498; E-mail: rashi.khanna-jain@uta.fi

Received July 21, 2012; Accepted August 16, 2012; Published August 18, 2012

Citation: Khanna-Jain R, Vanhatupa S, Vuorinen A, Sandor GKB, Suuronen R, et al. (2012) Growth and Differentiation of Human Dental Pulp Stem Cells Maintained in Fetal Bovine Serum, Human Serum and Serum-free/Xeno-free Culture Media. J Stem Cell Res Ther 2:126. doi:10.4172/2157-7633.1000126

Copyright: @ 2012 Khanna-Jain R, et al. This is an open-access article distributed under the terms of the Creative Commons Attribution License, which permits unrestricted use, distribution, and reproduction in any medium, provided the original author and source are credited. 
Citation: Khanna-Jain R, Vanhatupa S, Vuorinen A, Sandor GKB, Suuronen R, et al. (2012) Growth and Differentiation of Human Dental Pulp Stem Cells Maintained in Fetal Bovine Serum, Human Serum and Serum-free/Xeno-free Culture Media. J Stem Cell Res Ther 2:126. doi:10.4172/2157-7633.1000126

problems encountered by expanding and differentiating cells in Fetal Bovine Serum (FBS) which are associated with possible allergic reactions caused by FBS proteins internalized in the stem cells and risks of transmitting viruses, prions, bacteria, yeast or endotoxins upon transplantation $[21,22,23]$. Also, the concentration of growth factors or bulk proteins in complex FBS may vary between lot to lot [24], hence leading to difficulty in maintaining a consistent cell culture protocol. To address these problems, various alternatives have been explored by several investigators to maintain proliferation and differentiation of MSCs. Among these are human blood derived alternatives such as autologous human serum (autoHS), allogenic Human Serum (alloHS) [25], human platelet lysates [26], umbilical cord blood serum [27] and autologous plasma derived from bone marrow (AP) [28]. There are several investigations on the efficacy of alloHS, autoHS and $\mathrm{AP}$ as an option to FBS for BM-MSCs culture $[29,30]$ but none for DPSCs. However, conflicting data on the use autoHS and alloHS has been reported, where the BM-MSCs proliferated at a slower rate and diminished differentiation capability was observed [31,32]. Conversely, autoHS and alloHS have been reported to maintain the proliferation and differentiation of MSCs as effectively as FBS $[33,34,35]$. Most recently, a study conducted in vitro and in vivo showed that HS was as efficient as FBS in supporting proliferation and differentiation of BM-MSCs [30]. In order to overcome the inconsistent performance associated with HS, a robust serumfree/ xenofree medium (SF/XF-M) for MSCs culture has to be developed. The use of chemically defined SF/XF-M could result in eliminating lot to lot variability issues, possible immune reactions and associated complications [36]. Interestingly, a study from our group has shown the ability of adipose tissue derived mesenchymal stem cells (AD-MSCs) to maintain the multipotent differentiation capacity and to proliferate better in SF/XF conditions in comparison to HS and FBS culture conditions [37], whereas, there are lack of reports related to the response of SF/XF medium on DPSCs. However, the effect of different serum free media comprising of xenogenic growth factors on DPSCs proliferation or colony formation have been reported [38].

Taken together, it is important to elucidate the effect of HS and SF/XF media on DPSCs isolation and expandability before using them for clinical therapies. In this study, DPSCs were expanded in HS or SF/XF media by using xenofree supplements to limit the possibility of xenogenic contaminations. We studied the morphology, cell surface marker expression and proliferation rate of the DPSCs cultured in FBS, HS or SF/XF media. Subsequently, we studied expression of cell surface stage-specific embryonic antigen (SSEA)-4 as well as intracellular stemness markers octamer-binding transcription factor (Oct3/4), SRY (sex determining region Y) box-2 (Sox2) and Nanog to further analyze the stemness of DPSCs cultured in different media. Moreover, we investigated the multilineage differentiation potential of DPSCs into osteogenic, adipogenic and chondrogenic lineages in different culture conditions.

\section{Material and Methods}

\section{Cell isolation and culture}

Human impacted third molars were obtained with informed written consent from Finnish Student Health Services, Tampere, Finland. The Ethics Committee, of the Pirkanmaa Hospital District, Tampere, Finland (R06009), approved the collection of stem cells from tooth samples specifically for this study. Human dental pulp explants were obtained from partially or completely impacted third molar teeth of 4 patients, aged 21-26 years $(23 \pm 2.5$ years). The pulp tissue explants were brought from the health centre to the laboratory in Dulbecco's Phosphate buffered saline (PBS; BioWhittaker Lonza, Verviers, Belgium) containing $2 \%$ antibiotics/antimycotics (a/a; $100 \mathrm{U} /$ $\mathrm{ml}$ penicillin, $0.1 \mathrm{mg} / \mathrm{mL}$ streptomycin and $0.25 \mu \mathrm{g} / \mathrm{mL}$ amphotericin B; Life Technologies, Paisley, Scotland, UK). The dental pulp tissue fragments were minced by using sterilized scalpels and digested in collagenase type I $3 \mathrm{mg} / \mathrm{ml}$ (Invitrogen) and dispose $4 \mathrm{mg} / \mathrm{ml}$ (Invitrogen) for 1 hour at $37^{\circ} \mathrm{C}$. Once digestion was completed the obtained cell pellet was suspended in $600 \mu \mathrm{l}$ of PBS and was passed through a $100 \mu \mathrm{m}$ cell strainer (Falcon, BD Labware, Franklin lakes, NJ, USA). The isolated dental pulp stem cells (DPSCs) were cultured in two different media (1) Dulbecco's modified Eagle medium (DMEM)/F-12 1:1 (Gibco Life Technologies, Paisley, UK) supplemented with $1 \%$ l-analyl-l-glutamine (Gluta-MAX I; Life Technologies), 1\% a/a and $10 \%$ fetal bovine serum (FBS; Invitrogen, Paisley, UK) (FBS-M) and (2) (DMEM)/F-12 1:1 supplemented with Gluta-MAX I, 1\% a/a and $20 \%$ allogenic Human Serum (HS; PAA Laboratories GmbH, Pasching, Austria) (HS-M)

Further, DPSCs expanded in HS-M were used for testing StemPro ${ }^{\circ}$ MSC xenofree, serumfree/xenofree medium (SF/XF-M; Life Technologies), where culture wells were coated with CELLstart (Life Technologies) to assist in cell attachment (Table 1). Initially, DPSCs were directly cultured in SF/XF-M on carboxyl, amine (BD Biosciences) or CELLstart coated culture plates but cells did not proliferate; therefore, cells cultured in HS-M were later cultured in SF/

\begin{tabular}{|c|c|c|c|c|c|c|}
\hline Medium & Abbreviation & $\begin{array}{l}\text { Basal } \\
\text { medium }\end{array}$ & Serum & Xenofree & Coating & Supplementation \\
\hline $\begin{array}{l}\text { Fetal } \\
\text { Bovine } \\
\text { Serum- } \\
\text { Medium }\end{array}$ & FBS-M & $\begin{array}{l}\text { DMEM/F } \\
-12\end{array}$ & $\begin{array}{l}10 \% \\
\text { FBS }\end{array}$ & No & No & $\begin{array}{l}1 \% \text { GlutaMAX, } \\
1 \% \text { ala }\end{array}$ \\
\hline $\begin{array}{l}\text { Human } \\
\text { Serum- } \\
\text { Medium }\end{array}$ & HS-M & $\begin{array}{l}\text { DMEM/F } \\
-12\end{array}$ & $\begin{array}{l}20 \% \\
H S\end{array}$ & Yes & No & $\begin{array}{l}1 \% \text { GlutaMAX, } \\
1 \% \text { ala }\end{array}$ \\
\hline $\begin{array}{l}\text { Serum Free/ } \\
\text { XenoFree- } \\
\text { Medium } \\
\text { (Stem Pro® } \\
\text { MSC SFM } \\
\text { XenoFree) }\end{array}$ & SF/XF-M & $\begin{array}{l}\text { Stem } \\
\text { Pro® } \\
\text { MSC } \\
\text { SFM } \\
\text { xenofree }\end{array}$ & No & Yes & $\begin{array}{l}\text { CELLstart } \\
\text { (Life } \\
\text { Technologies) }\end{array}$ & $\begin{array}{l}\text { Stem Pro® MSC } \\
\text { SFM Xeno Free } \\
\text { supplement, } 1 \% \text { a/a }\end{array}$ \\
\hline
\end{tabular}

Table 1: Different culture media to test the growth of DPSCs. Dulbecco's modified eagle medium (DMEM/F-12) containing fetal bovine serum (FBS-M), human serum (HS-M) and serumfree/xenofree (SF/XF-M). 
Citation: Khanna-Jain R, Vanhatupa S, Vuorinen A, Sandor GKB, Suuronen R, et al. (2012) Growth and Differentiation of Human Dental Pulp Stem Cells Maintained in Fetal Bovine Serum, Human Serum and Serum-free/Xeno-free Culture Media. J Stem Cell Res Ther 2:126. doi:10.4172/2157-7633.1000126

XF medium for all the experiments, as described in (Figure 1). DPSCs isolated and expanded in FBS-M were harvested using 1\% trypsin (Lonza/BioWhittaker, Verviers, Belgium). The DPSCs isolated and cultured in HS-M and SF/XF-M were harvested using TrypLE Select (Life Technologies) for XF detachment of cells. Cell culture plates and T-75 culture flasks (Thermo Fischer, Nunc; Roskilde, Denmark) were monitored daily for cell growth, with medium changes taking place three times per week (Table 1). All assays were performed using cells between passage 3-4 and experiments were repeated using DPSCs derived from 4 different donors.

\section{Immunocytochemistry}

For immunocytochemistry, 2500 cells/ well were plated on 48 well plates. After 3 days of culturing, cells were fixed with $4 \%$ paraformaldehyde (Fluka, Italy) containing $0.2 \%$ of TritonX-100. After fixation, cells were stained with stemness markers. Briefly, unspecific staining was blocked with $1 \%$ bovine serum albumin (BSA, SigmaAldrich) in PBS for $45 \mathrm{~min}$ at room temperature. The cells were washed 2-3 times with PBS. Thereafter, the primary antibodies; goat anti-octamer-binding transcription factor (Oct) 3/4, mouse anti-SRY (sex determining region Y) box-2 (Sox2) and goat anti-Nanog (all: R\&D Systems) as well as mouse anti-stage specific embryonic antigen (SSEA)-4 (Santa Cruz) in 1\% BSA-PBS solution were incubated with cells at $+4^{\circ} \mathrm{C}$, overnight. Next day, the cells were washed three times with PBS and were incubated in secondary antibodies, Alexa Fluor 488 and 568 conjugated to anti-goat and anti-mouse (Molecular Probes, Invitrogen) in $1 \%$ BSA-PBS for $1 \mathrm{~h}$ at room temperature. Finally, cells were washed three times with PBS, twice with water and mounted with Vectashield containing 4', 6-diamidino-2-phenylindole (DAPI, Vector Laboratories, England) to identify nuclei. Cell samples were analyzed by using an Olympus IX51 phase-contrast microscope equipped with fluorescence unit and an Olympus DP30BW camera (Olympus).

\section{Flow cytometric surface marker expression analysis}

DPSCs cultured in FBS-M, HS-M and SF/XF-M and were analyzed for cell surface antigen expression by flow cytometry (FACSAria ${ }^{\circ}$; BD Biosciences, Erembodegem, Belgium). Monoclonal antibodies (MAb) against CD29-Allophycocyanin (APC), CD44-Phycoerythrin (PE), CD90-APC, CD45-APC, CD146-PE (BD Biosciences), CD105PE (R\&D Systems Inc., Minneapolis, MN, USA), CD31-fluorescein isothiocyanate (FITC) (Immunotools GmbH, Friesoythe, Germany), and major histocompatibility class II antigen (HLA-DR)-PE (Immunotools) were used. FACS analysis was performed on 100,000 cells/sample and the positive expression was defined as the level of fluorescence greater than $99 \%$ of the corresponding unstained cell sample.

\section{Cell proliferation assay}

This assay was done to measure the viability and induction of DPSCs proliferation when cultured in FBS-M, HS-M in different serum conditions $(5 \%, 10 \%, 15 \%, 20 \%)$, SF/XF-M or SF/XF-M with 1 or $5 \%$ of HS. The DPSCs $(n=4)$ were seeded on a 48 or 24 -well plate at a density of 2500 or 5000 cells/well, depending on well format. The SF/XF-M culture wells were pre-coated with CELLstart. Cell proliferation was quantified at 1, 4, 7 and 14 days using the colorimetric reagent WST1 (Takara Bio Inc, Otsu, Japan) for comparing the effect of FBS-M, $15 \%$ HS-M and SF/XF-M cultured cells. Briefly, WST-1 reagent was added to each well containing fresh medium (50 $\mu \mathrm{l}$ of WST-1/ $500 \mu \mathrm{l}$ of medium in each well of 24 -well plate), incubated for $60 \mathrm{~min}$. For HS serum concentration gradient $(5 \%, 10 \%, 15 \%, 20 \%)$ growth assay (Figure $5 \mathrm{~B}$ ) and for comparative $\mathrm{SF} / \mathrm{XF}$ and $\mathrm{SF} / \mathrm{XF}+\mathrm{HS}(1 \%$ and $5 \%$ ) growth assay (Figure 5C) cells were washed with PBS and $20 \mu \mathrm{l}$ of WST-1 reagent in addition to $200 \mu \mathrm{PBS}$ was added to each well. The plate was incubated for 4 hours at $37^{\circ} \mathrm{C}$ prior to the measurement. The absorbance was measured at $450 \mathrm{~nm}$ using a microplate reader Victor 1420 (Perkin Elmer life Sciences, Turku, Finland).

\section{In vitro multilineage differentiation analysis}

DPSCs $(n=4)$ were examined for their ability to differentiate toward the adipogenic, osteogenic and chondrogenic lineages by quantitative real time-polymerase chain reaction (qRT-PCR) and lineage specific stainings. Briefly, for osteogenic and adipogenic differentiation analysis cells were seeded at a density of 5000 cells/well on a 24 well plate in FBS-M, HS-M or SF/XF-M. After 24 hours, osteogenic differentiation medium $(\mathrm{OM})$ and adipogenic differentiation medium (AM) were added for each serum culture condition as stated in Table 2. The chondrogenic differentiation of DPSCs was assessed by using micromass cell culture method. Briefly, 100,000 cells were seeded on a 24 well plate in a $10 \mu \mathrm{l}$ volume of FBS-M, HS-M or SF/XF-M, that were let to adhere for 3 hours in an incubator prior to the addition of chondrogenic differentiation medium (CM) as described in Table 2. For all the analyses the control cultures were maintained in FBS-M, HS-M or SF/XF-M. The SF/XF-M culture wells were pre-coated with CELLstart for osteogenic and adipogenic differentiation while for chondrogenic micro mass aggregate formation, the culture wells were not coated. All cultures were maintained for 21 days for the differentiation analysis.

\section{Alizarin red staining}

In vitro mineralization was induced by FBS-OM, HS-OM or SF/ XF-OM and was analyzed by alizarin red staining after 21 days. Briefly, cells were fixed in ice-cold $70 \%$ ethanol for $60 \mathrm{~min}$ at $-20^{\circ} \mathrm{C}$. Then, cells were washed twice with distilled water and stained with $40 \mathrm{mM}$ Alizarin red S solution (Sigma) for $10 \mathrm{~min}$ at room temperature. The $\mathrm{pH}$ value of the solution was adjusted to 4.2 with $25 \%$ ammonium hydroxide prior to staining. After staining, excess dye was washed with distilled water and digital images of stained mineral deposits were taken.

\section{Alcian blue staining}

After 21 days of culture, the chondrogenically induced micro

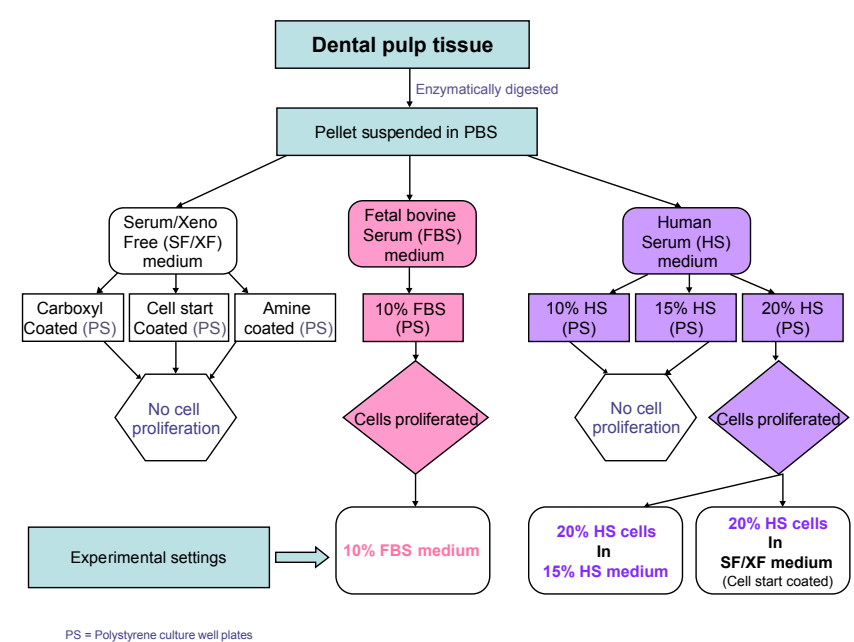

Figure 1: Flowchart representing effects of different cell culture media on isolation of dental pulp stem cells (DPSCs) and showing the final experimental settings. 
Citation: Khanna-Jain R, Vanhatupa S, Vuorinen A, Sandor GKB, Suuronen R, et al. (2012) Growth and Differentiation of Human Dental Pulp Stem Cells Maintained in Fetal Bovine Serum, Human Serum and Serum-free/Xeno-free Culture Media. J Stem Cell Res Ther 2:126. doi:10.4172/2157-7633.1000126

masses were fixed in $4 \%$ paraformaldehyde (PFA) for 60 mins. The micro masses were then embedded in paraffin, and sectioned at a thickness of $5 \mu \mathrm{m}$ for histological evaluation. The undifferentiated and differentiated micro masses sections were stained with $0.5 \%$ Alcian blue stain and counterstained with Nuclear Fast Red solution (Biocare Medical, Concord, MA, USA). The stained micromass sections were viewed under the microscope to evaluate the proteoglycan content.

\section{Oil O Red staining}

DPSCs were stained with $0.3 \%$ Oil Red O-solution to detect the accumulation of extracellular lipid droplets after 21 days of culture in FBS-AM, HS-AM and SF/XF-AM. Briefly, cells were fixed with $4 \%$ PFA for 60 mins. Further the cells were rinsed with distilled water and incubated in $60 \%$ isopropanol for 5 mins. Thereafter, the cells were stained with Oil $\mathrm{O}$ red solution for $15 \mathrm{mins}$ at room temperature. Following the staining the wells were washed thoroughly to remove the excess stain and microscopic images were taken.

\section{QRT-PCR}

The cell culture conditions were same as described above in in vitro multilineage differentiation analysis. The total RNA was extracted at 21 days time point by Eurozol (Euroclone S.p.A, Pero, Italy). First-strand cDNA syntheses were performed by a High Capacity cDNA Archive Kit (Applied Biosystems, Warrington, UK). Quantitative RT-PCR was conducted using RPLP0 (human acidic ribosomal phosphoprotein) as the house keeping gene and lineage specific primers such as for osteogenic differentiation: osteocalcin (OCN) and osteopontin (OPN), chondrogenic differentiation; SRY (Sex determining Region Y)-box 9 (SOX9) and Type X collagen alpha-1 (COL10A1) and adipogenic differentiation; fatty acid binding protein 4 (aP2) and human peroxisome proliferator-activated receptor gamma (hPPARG) and stemness markers; Oct3/4, Sox 2 and Nanog (Table 3). To exclude signals from contaminating DNA, the forward and reverse sequence of each primer were designed on different exons. The Power SYBR Green PCR Master Mix (Applied Biosystems) was used for quantitative PCR reactions according to the manufacturer's instructions. The reactions were performed with AbiPrism 7300 Sequence Detection System (Applied Biosystems) at $95^{\circ} \mathrm{C} 10 \mathrm{~min}$, and then 45 cycles at $95^{\circ} \mathrm{C} / 15$ $\mathrm{s}$ and $60^{\circ} \mathrm{C} / 60 \mathrm{~s}$. The $\mathrm{Ct}$ values for OCN, OPN, SOX9, COL10A1, AP2 PPARG, Oct3/4, Sox2 and Nanog were normalized to that of the housekeeping gene RPLP0, as described elsewhere [39].

\section{Statistical analysis}

The statistical analyses of the results were performed with GraphPad Prism 5.01. The data is presented as mean \pm standard deviation (SD) for all quantitative assays and experiments were carried out in triplicate for cells derived from three donor samples. One-way analysis of variance (ANOVA) with Bonferroni post hoc test for multiple comparisons was used for the statistical analysis. All statistical analyses were performed at the significance level $\mathrm{p}<0.05$.

\section{Results}

\section{Derivation of DPSCs in different culture conditions}

DPSCs were enzymatically isolated from dental pulp tissue of healthy individuals and suspended in PBS. The isolated dental pulp cells suspension in PBS was used to test the effect of different media on cell culture. We found that the cells directly isolated on carboxyl, CELLstart and amine coated culture wells in SF/XF medium, did not proliferate. Additionally, cells directly isolated in $10 \%$ or $15 \%$ HS-M did not proliferate; therefore, cells were isolated in $20 \%$ HS-M. However, after first passage, 15\% HS-M supported DPSCs expansion. In addition, cells isolated in $20 \%$ HS-M were able to proliferate in SF/ XF-M medium, thus, we were able to maintain xenofree conditions for cell culture. DPSCs directly isolated in 10\% FBS-M proliferated. Based on these findings, isolated dental pulp cells suspended in PBS were directly divided and cultured in 1) 10\% FBS and 20\% HS-M. Further, $20 \%$ HS-M cultured cells were expanded in 2) $15 \%$ HS-M and in 3) SF/ XF-M constituting of our final experimental settings as described in (Figure 1).

\begin{tabular}{|c|c|c|c|}
\hline Medium & Basal Media & Serum & Supplementation \\
\hline $\begin{array}{l}\text { Control } \\
\text { (FBS-M, HS-M, SF/XF- } \\
\text { M) }\end{array}$ & DMEM/F-12, SF/XF-M & $\begin{array}{l}10 \% \text { FBS or } \\
15 \% \text { HS or no } \\
\text { serum }\end{array}$ & None \\
\hline $\begin{array}{l}\text { Osteogenic Medium } \\
\text { (OM; FBS-OM, HS-OM, } \\
\text { SF/XF-OM) }\end{array}$ & DMEM/F-12, SF/XF-M & $\begin{array}{l}10 \% \text { FBS or } \\
15 \% \text { HS or no } \\
\text { serum }\end{array}$ & $\begin{array}{l}50 \mu \mathrm{M} \text { L- ascorbic acid (Sigma), } 10 \\
\mathrm{mM} \text { beta glycerophosphate (Sigma), } \\
100 \mathrm{nM} 1,25 \text { hydroxy Vitamin } \mathrm{D}_{3} \\
\text { (VD; Sigma), } 1 \% \text { a/a, } 1 \% \text { GlutaMAX }\end{array}$ \\
\hline $\begin{array}{l}\text { Adipogenic Medium } \\
\text { (AM; FBS-AM, HS-AM, } \\
\text { SF/XF-AM) }\end{array}$ & DMEM/F-12, SF/XF-M & $\begin{array}{l}10 \% \text { FBS or } \\
15 \% \text { HS or no } \\
\text { serum }\end{array}$ & $\begin{array}{l}33 \mu \mathrm{M} \text { biotin (Sigma) } 1 \mu \mathrm{M} \\
\text { dexamethasone (Sigma), } 100 \mathrm{nM} \\
\text { insulin (life technologies), } 17 \mu \mathrm{M} \\
\text { pantothenate (Fluka), } 1 \% \text { GlutaMAX, } \\
\text { and } 1 \% \text { a/a. Upon seeding of cells, } \\
250 \mu \mathrm{M} \text { of isobutylmethylxanthine } \\
\text { (IBMX; Sigma) was added for } 72 \\
\text { hours }\end{array}$ \\
\hline $\begin{array}{l}\text { Chondrogenic Medium } \\
\text { (CM) }\end{array}$ & DMEM/F-12, SF/XF-M & No serum & $\begin{array}{l}\text { Insulin Transferrin-Selenium+1 } \\
\text { (Sigma), } 50 \mu \mathrm{M} \text { L- ascorbic acid, } \\
55 \mu \mathrm{M} \text { sodium pyruvate (Life } \\
\text { Technologies), } 23 \mu \mathrm{M} \text { L-proline } \\
\text { (Sigma), } 1 \% \text { GlutaMAX and } 1 \% \text { a/a. } \\
\text { TGF- } \beta 1 \text { (Sigma) }\end{array}$ \\
\hline
\end{tabular}

Table 2: Lineage specific differentiation induced by media supplements. 
Citation: Khanna-Jain R, Vanhatupa S, Vuorinen A, Sandor GKB, Suuronen R, et al. (2012) Growth and Differentiation of Human Dental Pulp Stem Cells Maintained in Fetal Bovine Serum, Human Serum and Serum-free/Xeno-free Culture Media. J Stem Cell Res Ther 2:126. doi:10.4172/2157-7633.1000126

Page 5 of 11

\begin{tabular}{|c|c|c|c|}
\hline Gene Name & 5'-sequence-3' & Product size & Accession number \\
\hline RPLPO & $\begin{array}{l}\text { Forward AATCTCCAGGGGCACCATT } \\
\text { Reverse CGTTGGCTCCCACTTTGT }\end{array}$ & 70 & NM_001002 \\
\hline $\mathrm{OCN}$ & $\begin{array}{l}\text { Forward AGCAAAGGTGCAGCCTTTGT } \\
\text { Reverse GCGCCTGGGTCTCTTCACT }\end{array}$ & 63 & NM_000711 \\
\hline OPN & $\begin{array}{l}\text { Forward GCCGACCAAGGAAAACTCACT } \\
\text { Reverse GGCACAGGTGATGCCTAGGA }\end{array}$ & 71 & J04765 \\
\hline SOX9 & $\begin{array}{l}\text { Forward AAAGGCAACTCGTACCCAAATTT } \\
\text { Reverse TGATTGGCCACAAGTGGGTAA }\end{array}$ & 75 & NM_000346 \\
\hline COL10A1 & $\begin{array}{l}\text { Forward CACGCAGAATCCATCTGAGAATAT } \\
\text { Reverse GTTCAGCGTAAAACACTCCATGAA }\end{array}$ & 92 & NM_000493 \\
\hline PPARG & $\begin{array}{l}\text { Forward CAGTGTGAATTACAGCAAACC } \\
\text { Reverse ACAGTGTATCAGTGAAGGAAT }\end{array}$ & 100 & NM_015869 \\
\hline AP2 & $\begin{array}{l}\text { Forward GGTGGTGGAATGCGTCATG } \\
\text { Reverse CAACGTCCCTTGGCTTATGC }\end{array}$ & 71 & NM_001442 \\
\hline ОСТ3/4 & $\begin{array}{l}\text { Forward GACAGGGGGAGGGGAGGAGCTAGG } \\
\text { Reverse CTTCCCTCCAACCAGTTGCCCAAAC }\end{array}$ & 118 & NM_002701 \\
\hline SOX2 & $\begin{array}{l}\text { Forward GGGAAATGGGAGGGGTGCAAAAGAGG } \\
\text { Reverse TTGCGTGAGTGTGGATTGGTG }\end{array}$ & 125 & NM_003106 \\
\hline NANOG & $\begin{array}{l}\text { Forward AAAGAATCTTCACCTATGCC } \\
\text { Reverse GAAGGAAGAGGAGAGACAGT }\end{array}$ & 111 & NM_024865 \\
\hline
\end{tabular}

Table 3: Primers sequence for quantitative RT-PCR.

\section{Stemness marker expression}

DPSCs isolated in $20 \%$ HS culture medium were analyzed by immunocytochemical staining with Oct3/4 and Sox2 markers (Figure 2). Oct $3 / 4$ and Sox 2 were equally expressed in all samples depicting the stemness potential of DPSCs cultured in HS-M. Additionally, when nuclear (Dapi) and stemness markers (Oct3/4, Sox2) stainings were merged they resulted in nearly complete overlap, indicating that majority of DPSCs are Oct3/4 and Sox 2 positive (Figure 2A-F). The expression of stemness markers Nanog and SSEA-4 was also studied in SF/XF, HS and FBS culture conditions by immunostaining and results indicate that DPSCs also express Nanog and SSEA-4 (Supplementary Figure 1).

The mRNA expression of Oct3/4, Sox 2 and Nanog were analysed in cells cultured in SF/XF, HS and FBS media by qRT-PCR. Results shown in Figure 2G suggest that stemness markers were expressed at mRNA level; however, Oct $3 / 4$ was significantly upregulated $(\mathrm{p}<0.05)$ in FBS and HS media cultured cells when compared with SF/XF-M cultured cells. Moreover, no significant differences in Sox2 and Nanog expression were observed between different cell culture conditions.

\section{Morphological differences}

The morphology of human DPSCs expanded in FBS-M, HS-M or SF/XF-M was compared by using phase contrast microscopy. Cells cultured in FBS appeared broader and flattened in shape, whereas cells cultured in HS-M were more fibroblastic and appeared more homogenous. Moreover, cells expanded in SF/XF-M exhibited a more flattened fibroblastic like morphology (Figure 3). Similar morphological differences were observed by FACS analysis, DPSCs cultured in FBS-M, HS-M or SF/XF-M differed in cell size and granularity as assessed by the forward and side scatter (Figure 4A). The cells cultured in FBS-M displayed larger cell size and greater heterogeneity. On the other hand, cells cultured in HS-M and SF/XF-M were more homogenous and smaller in cell size.

\section{Cell surface marker expression}

Furthermore, DPSCs expanded in different culture media were analyzed using flow cytometry for mesenchymal markers CD29, CD44, CD90 and CD105; hematopoietic and angiogeneic markers CD31, CD45, CD146 and for HLA-DR. FACS analysis displayed that DPSCs cultured in different media showed positive expression for the mesenchymal marker $(>50 \%)$ and for CD146 perivascular marker (Figure 4A and 4B). However, results related to CD146 marker expression varied between patient samples. Moderate expression $(<30 \%)$ of CD45 was observed but DPSCs lacked the expression for CD31 hematopoietic marker. In addition, DPSCs cultured in FBS-M, HS-M and SF/XF-M lacked the expression of HLA-DR (Figure 4C and 4D). Also, there were no statistical significant differences (Figure 4B and $4 \mathrm{D}$ ) observed between the expression profile of cells cultured in FBS-M, HS-M and SF/XF-M due to variability between patient samples.

\section{Cell proliferation}

The effects of FBS-M, HS-M and SF/XF-M on DPSCs growth were analyzed following days 1, 4, 7 and 14. The cells cultured in SF/XF-M proliferated slowly in comparison to the cells cultured in FBS and HS medium, which was observed from day 4 . Statistical analysis revealed that cells cultured in FBS-M and HS-M proliferated significantly faster than cells cultured in SF/XF-M at day 7 to day 14 ( $\mathrm{p}<0.001$ ) (Figure $5 \mathrm{~A}$ ). Moreover, no significant differences were observed between cells cultured in FBS-M and HS-M.

In Figure 5B, we have shown the effect of 5\%, 10\%, 15\% and 20\% HS concentrations on passaged DPSCs proliferation after initial isolation of cells in $20 \%$ HS. At day 7, the cells cultured in $10 \%, 15 \%$ and $20 \%$ showed significant increase $(\mathrm{p}<0.001)$ in cell numbers when compared with $5 \%$ HS cultured cells. Interestingly, on day 14 there was significant increase in cell proliferation in cells cultured in 15\% HS ( $p<0.001)$ when compared with $10 \% \mathrm{HS}$, and even higher cell proliferation was observed in $20 \%$ HS cultured cells ( $\mathrm{p}<0.001)$. Moreover, proliferation of cells cultured in $5 \%$ HS concentration was significantly slower in comparison to $10 \%, 15 \%$ and $20 \%(\mathrm{p}<0.001)$.

Furthermore, as shown in Figure 5A, SF/XF-M resulted in slower cell proliferation in comparison to the FBS-M and HS-M. Therefore, we speculated to see better cell proliferation by the addition of HS in the SF/XF-M. The results in Figure 5C, show that at day 4 the cells cultured in SF/XF-M + 5\% HS significantly increased proliferation $(\mathrm{p}<0.001)$ in comparison to other two conditions. However, SF/XF-M $+1 \%$ HS significantly increased cell proliferation following day $7(\mathrm{p}<0.001)$ and 14 ( $\mathrm{p}<0.05)$, in comparison to SF/XF-M alone and SF/XF-M + 5\% HS 
Citation: Khanna-Jain R, Vanhatupa S, Vuorinen A, Sandor GKB, Suuronen R, et al. (2012) Growth and Differentiation of Human Dental Pulp Stem Cells Maintained in Fetal Bovine Serum, Human Serum and Serum-free/Xeno-free Culture Media. J Stem Cell Res Ther 2:126. doi:10.4172/2157-7633.1000126

\section{Osteogenic differentiation}

The DPSCs were induced to differentiate towards osteogenic lineage with the addition of vitamin $\mathrm{D}_{3}$ in the osteogenic medium for 21 days. The alizarin red staining results showed that DPSCs cultured in FBS-OM and HS-OM formed mineralized matrix, however, the calcified matrix staining was more pronounced in cells cultured in HS-OM. On the other hand, cells cultured in SF/XF-OM did not mineralize and the cell proliferation was also very slow as observed upon microscopical analysis (Figure 6A). Afterwards, the osteoblast genes expression pattern for OCN and OPN in DPSCs cultured in FBS$\mathrm{OM}, \mathrm{HS}-\mathrm{OM}$ and SF/XF-OM were analyzed at mRNA level (Figure 6B and $6 \mathrm{C}$ ). Similar to the staining results, the cells cultured in FBS-OM (p $<0.05)$ and HS-OM $(\mathrm{p}<0.05)$ upregulated OCN levels when compared with cells cultured in FBS-M. Cells cultured in SF/XF-OM regulated OCN expression at a very low level non-significantly. Moreover, OPN expression was upregulated by cells cultured in FBS-OM $(\mathrm{p}<0.01)$. Even though OPN levels were upregulated by cells cultured in HS-OM, the results were non-significant due to variability in expression levels between patient samples.

\section{Chondrogenic differentiation}

Chondrogenesis was estimated after staining the micro masses cultured in CM after 21 days, with Alcian blue stain, which stains the proteoglycan rich extracellular matrix. Cells isolated in FBS, HS or SF/XF media differentiated into chondrocytes-like cells when they were cultured in chondrogenic medium, however, more pronounced proteoglycan rich matrix was produced by cells isolated in FBS-M (Figure 7A). Following the staining, the mRNA expression of cells cultured in CM was analyzed. DPSCs isolated in FBS significantly upregulated SOX9 expression ( $\mathrm{p}<0.001)$, when the aggregates were differentiated in $\mathrm{CM}$ in comparison to undifferentiated aggregates cultured in FBS-M (Figure 7B). Moreover, expression of hypertrophic cartilage marker; Type $\mathrm{X}$ collagen was significantly increased in cells cultured in FBS $(\mathrm{p}<0.001)$ and HS $(\mathrm{p}<0.05)$ when they were induced with chondrogenic medium (Figure $7 \mathrm{C}$ ).
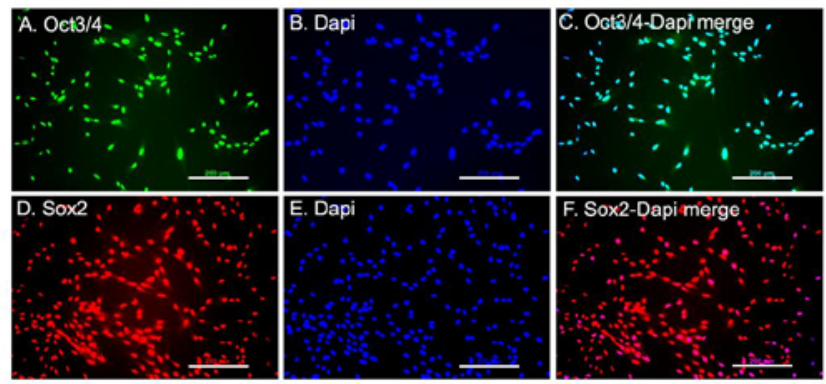

G
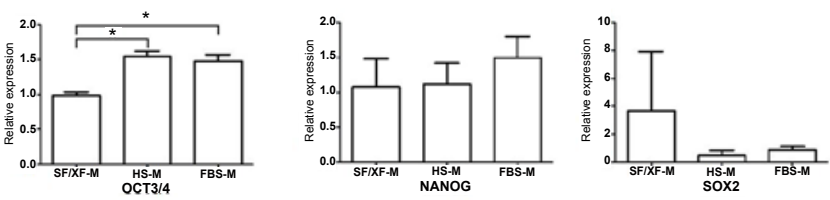

Figure 2: Stemness markers Oct3/4, Sox2 and Nanog are expressed in DPSCs. Immunostainings of intracellular stemness markers Oct3/4 (A), Sox2 (D) indicator of nuclei DAPI (B, E) and merged images of Oct3/4 and Dapi (C) and Sox2 and Dapi $(F)$. Scale bar $=200 \mu \mathrm{m}$. Gene expression of stemness markers were analyzed by qRT-PCR in different media, SF/XF-M, HS-M and FBS-M (G). Data represents the mean \pm SD and are normalized to housekeeping gene RPLPO. ( $\left.n=4,{ }^{*} p<0.05,{ }^{* *} p<0.01{ }^{* * *} p<0.001\right)$.
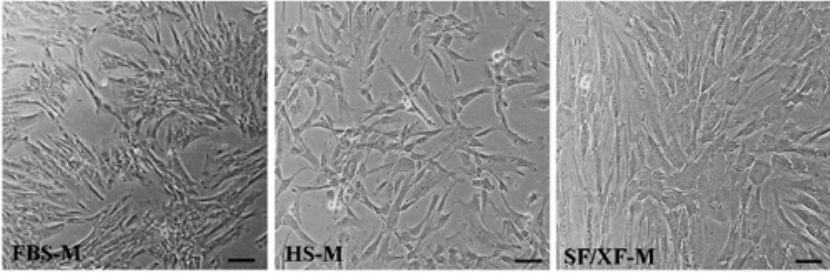

Figure 3: Morphology of DPSCs culture in (A) FBS-M were broader and flattened in shape (B) in HS-M cells appeared spindle-shaped and (C) in SF/XF-M cells appeared flattened fibroblastic. Scale bar $=100 \mu \mathrm{m}$. DPSCs: dental pulp stem cells; FBS-M: fetal bovine serum medium; HS-M: human serum medium; SF/XF-M: serumfree/xenofree medium.

\section{Adipogenic differentiation}

Differentiation into adipocytes was analyzed after 21 days of culturing the cells in AM by Oil Red O staining. DPSCs cultured in HS-AM had stronger capacity to differentiate into adipocytes than cells cultured in FBS-AM and SF/XF-AM. These results were assessed based on the higher number of accumulated lipid droplets. The potential of DPSCs to differentiate into adipocytes was also observed when the cells were cultured in HS-M without the addition of adipogenic differentiation supplements; however, DPSCs formed very few lipid droplets. Evident morphological differences were observed in cells differentiated in SF/XF-AM showing lipid vacuoles and rounded cell shape in comparison to cells cultured in control SF/XF-M (Figure 8A). Subsequently, the mRNA expression of adipogenic markers AP2 and hPPARG were analyzed and the results showed that although expression of both the markers were upregulated by cells cultured in FBS-AM, no statistically significant difference was found in comparison to cells cultured in FBS-M (Figure $8 \mathrm{~B}$ and $8 \mathrm{C}$ ). Moreover, DPSCs cultured in HS-AM significantly up regulated the expression of both AP2 and hPPARG ( $p<0.001, \mathrm{p}<0.01)$ in comparison to cells cultured in FBS-M. On the other hand, cells differentiated in SF/XF-AM and undifferentiated cells in SF/XF-M showed similar expression of both the markers despite of morphological differences.

\section{Discussion}

DPSCs obtained from impacted third molar teeth have been studied extensively for their excellent proliferation and multipotentional differentiation capacity [13-15,40,41]. There are several promising investigations describing the role of human DPSCs for mineralized tissue regeneration, advancing their therapeutic relevance as a valuable stem cell source [42-44]. However, in order to facilitate the translation of DPSCs from basic biology to clinical application, the development of appropriate cell culture protocols is a relevant and critical factor. Most commonly, DPSCs are cultured in FBS, which poses risk of transferring infections and induction of immune reactions upon transplantation $[23,24]$. With respect to the immuno pathogenic risks posed due to addition of FBS in cell culture, HS has been considered to be a safer alternative excluding the transfer of animal derived infections and related immunogenic reactions. But results related to MSCs cultured in HS are contradictory, some studies have reported successful isolation and differentiation of MSCs [30,35], whereas, others have observed slower cell proliferation or even growth arrest $[22,31]$. However, there is lack of information on the effect of HS in cultivation of DPSCs. In addition, other culture conditions comprising of chemically defined $\mathrm{SF} / \mathrm{XF}$ media have been researched that might serve as a better alternative and would bring about effective proliferation without 
Citation: Khanna-Jain R, Vanhatupa S, Vuorinen A, Sandor GKB, Suuronen R, et al. (2012) Growth and Differentiation of Human Dental Pulp Stem Cells Maintained in Fetal Bovine Serum, Human Serum and Serum-free/Xeno-free Culture Media. J Stem Cell Res Ther 2:126. doi:10.4172/2157-7633.1000126
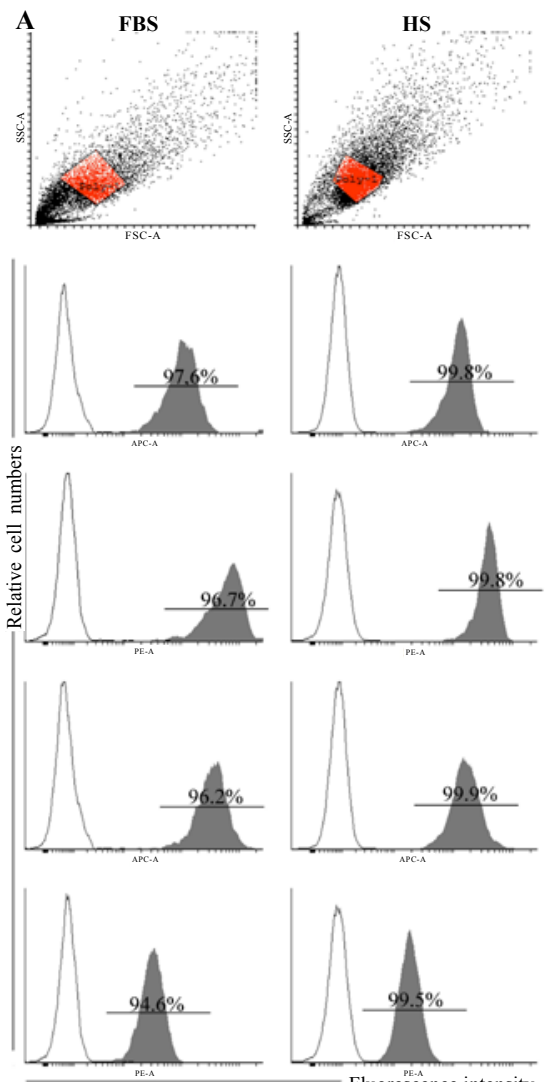

B

$$
\text { B }
$$

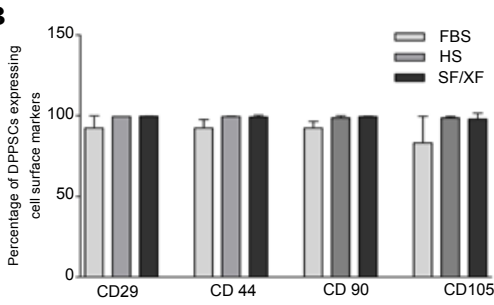

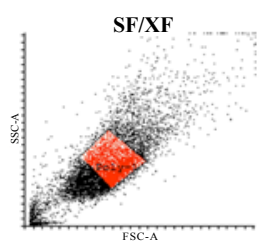
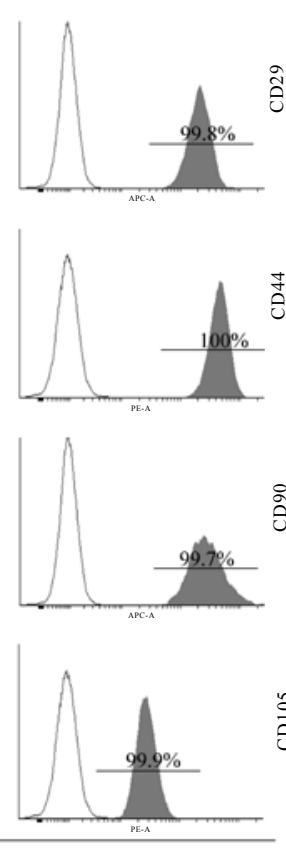

急

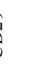

,
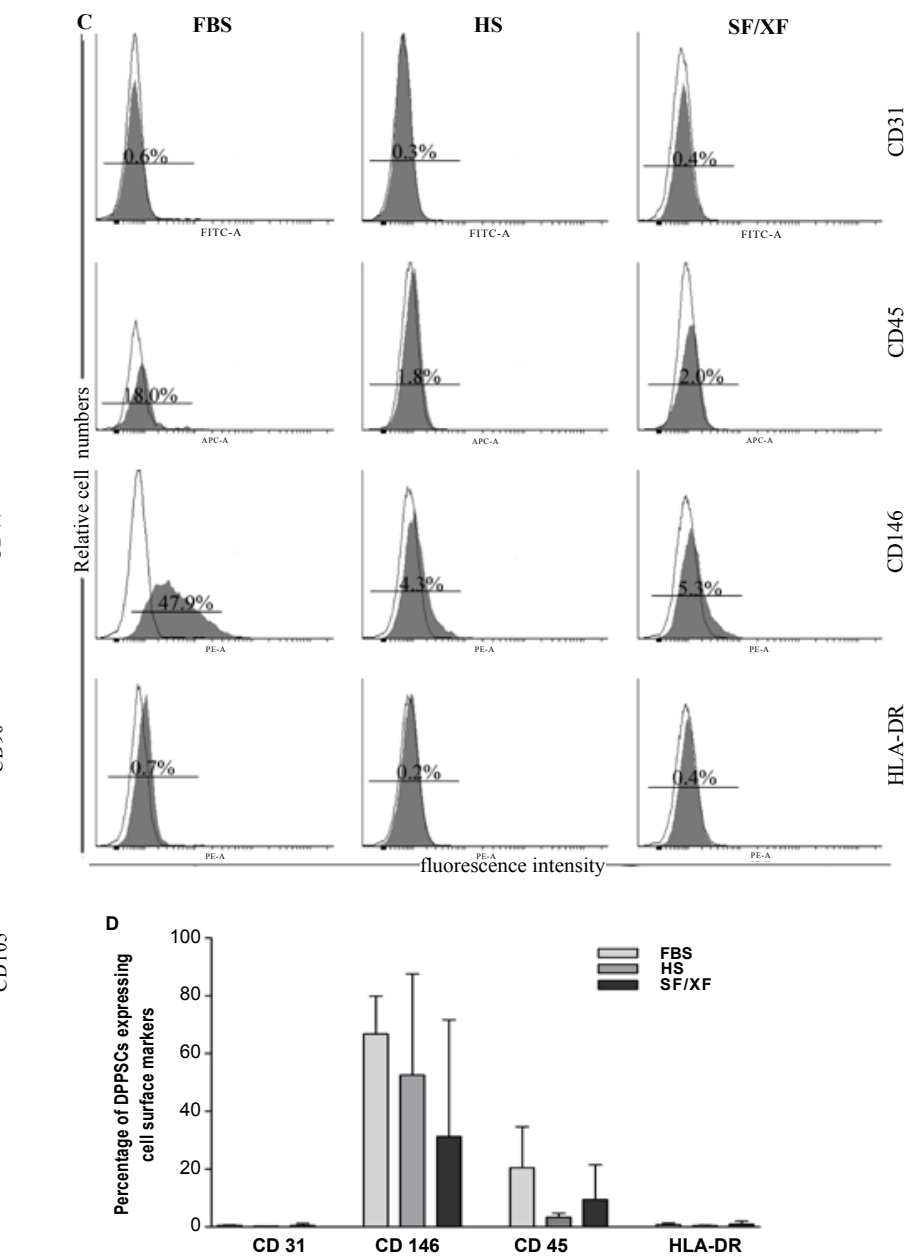

Figure 4: Surface marker expression of DPSCs cultured in FBS-M, HS-M and SF/XF-M was analyzed by flow cytometry. (A,C) Histograms demonstrating the forward and side scatter, relative cell count ( $y$-axis) and fluorescence intensity ( $x$-axis), with unstained control cells (empty histogram) and cells stained with antibodies against the surface proteins (filled histogram). (B,D) Column graph of flow cytometry data of surface marker expression levels, the bars represent the mean \pm SD $(n=4)$. DPSCs: dental pulp stem cells; FBS-M: fetal bovine serum medium; HS-M: human serum medium; SF/XF-M: serumfree/xenofree medium.

altering the cellular phenotypic features. There are reports showing the effects of serum free or low serum containing media on DPSCs cultures [38,45]. Nevertheless, DPSCs cultured in SF/XF medium, has not been reported, so far. Therefore, to safely produce DPSCs for clinical applications, in this present work we evaluated the response of FBS, HS or SF/XF media on isolation, expansion, morphology, phenotype, growth and multilineage differentiation potential of DPSCs.

In this study, we first sought to investigate the influence of FBS, HS and SF/XF media directly on cell isolation and proliferation. The cells isolated and cultured in FBS showed consistent proliferation, as reported in several publications [46,47]. Here, we have shown for the first time that $10 \%$ HS did not support the isolation of DPSCs, whereas, $20 \%$ HS supported the direct isolation and whereas, further expansion of the DPSCs was possible in lower HS concentrations $10 \%$ and $15 \%$. Intriguingly, in our study, DPSCs directly isolated in $\mathrm{SF} / \mathrm{XF}-\mathrm{M}$ and cultured on coated plates did not proliferate. Hence, cells isolated in 20\% HS-M were used to expand the cells in SF/XF-M which resulted in cell proliferation but at a very slow rate. However, in our study we elucidated the role of HS in SF/XF-M for increasing the cell proliferation. Interestingly, SF/XF-M $+1 \%$ HS showed increased DPSCs proliferation in comparison to SF/XF-M alone or SF/XF-M + $5 \%$ HS. Therefore, its important to note that SF/XF-M alone may not be sufficient for DPSCs growth, however, AD-MSCs have been reported to proliferate better in the same SF/XF-M [37], suggesting variability in responsiveness to SF/XF-M between different sources of MSCs. To our knowledge, this response to SF/XF-M and addition of HS has not been reported, however, other SF/XF-M compositions remains to be tested. Nonetheless, FBS and HS media cultivated DPSCs showed increased proliferation. Thus, these findings propose that HS was equally effective as FBS in supporting DPSCs proliferation, similar response has been successfully reported in other studies with BM-MSCs and AD-MSCs $[30,48,49]$.

Further, after assessing the adherence and proliferation, DPSCs cultured in different media were evaluated for cell surface markers 
Citation: Khanna-Jain R, Vanhatupa S, Vuorinen A, Sandor GKB, Suuronen R, et al. (2012) Growth and Differentiation of Human Dental Pulp Stem Cells Maintained in Fetal Bovine Serum, Human Serum and Serum-free/Xeno-free Culture Media. J Stem Cell Res Ther 2:126. doi:10.4172/2157-7633.1000126

Page 8 of 11
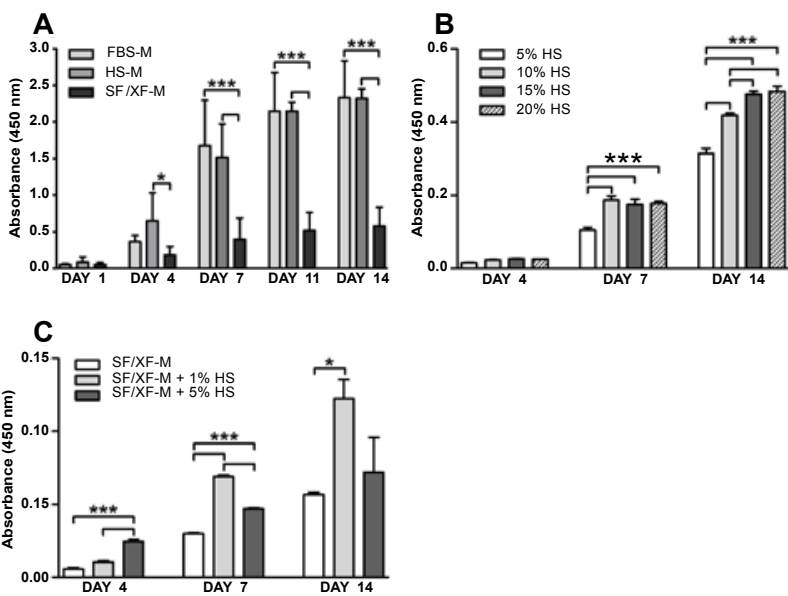

Figure 5: Response of FBS-M, HS-M and SF/XF-M on DPSCs proliferation assessed by WST-1 proliferation assay at day 1, 4, 7, 11 and 14. Cell proliferation in FBS-M, HS-M increased significantly from day 7 to 14 in comparison to cells cultured in SF/XF-M (A). Comparative analysis of DPSCs proliferation in varying concentrations of HS serum $5 \%-20 \%$. The significant increase in proliferation was observed in serum concentration $10 \%, 15 \%, 20 \%$ at day 7 and 14 in comparison to $5 \% \mathrm{HS}-\mathrm{M}$ (B). Cell proliferation in SF/XF-M $+1 \% \mathrm{HS}$ increased significantly from day 4 to 7 in comparison to SF/XF-M (C). The bars represent the mean \pm SD $(n=4$, asterisks indicate significant differences, ${ }^{*} p<0.05,{ }^{* *} p<0.01,{ }^{* * *} p<0.001$ ). DPSCs: dental pulp stem cells; FBS-M: fetal bovine serum medium; HS-M: human serum medium; SF/XF-M: serumfree/xenofree medium.
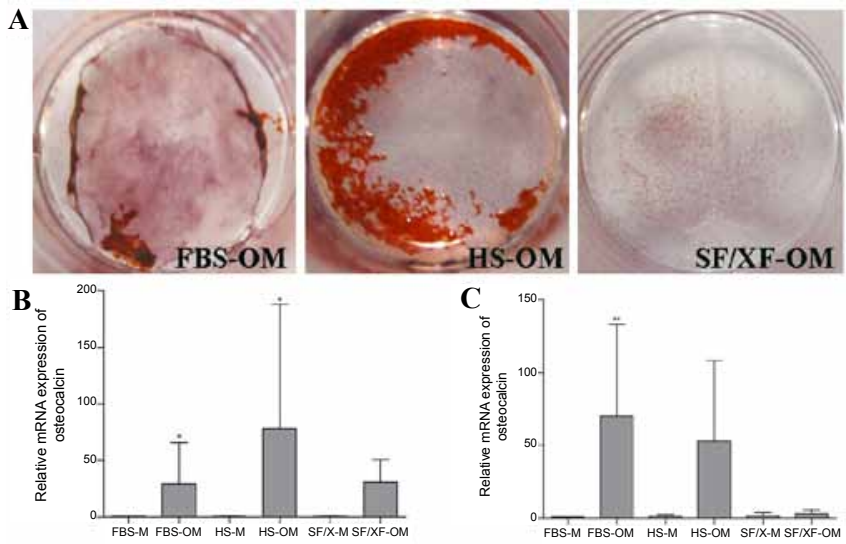

Figure 6: The osteogenic differentiation analysis for DPSCs cultured in FBS-OM, HS-OM and SF/XF-OM. Alizarin red stained the calcified mineralized matrix (A) and GRT-PCR analysis of osteogenic differentiation related gene expression for OCN (B) and OPN (C). Data represents the mean $\pm S D$ and are normalized to housekeeping gene RPLPO. $(n=4$, $\left.{ }^{*} p<0.05,{ }^{* *} p<0.01{ }^{* * *} p<0.001\right)$. (Online version in colour).

expression established to define them as MSCs [50]. DPSCs expressed CD29, CD44, CD90 and CD105 mesenchymal markers which are involved in MSCs migration, cell-cell matrix interaction and cell adhesion [37,51] and moderately expressed CD45 but lacked expression of CD31 hematopoietic markers and HLA-DR. Strikingly, we did not observe high variation in the expression of mesenchymal markers in DPSCs cultured in FBS, HS and SF/XF media conditions. This is especially important, since we have seen that cells cultured in SF/XF-M showed slower cell proliferation in comparison to FBS and HS. In view of the result, it is reasonable to speculate that serum is essential for cell attachment and proliferation of DPSCs, as suggested in a report [52]. However, the effect of other serum free/ xenofree media alternative needs to be elucidated further to delineate a definitive response on DPSCs. Furthermore, it is previously suggested that DPSCs originate from perivascular niche [53]. In view of the perivascular marker CD146 expression, we observed highest variability between four patient DPSCs samples tested which were cultured in the FBS-M, HS-M and SF/XF-M.

Recent findings have proposed that cell surface antigen SSEA4 as well as intracellular stemness markers Oct3/4, Sox 2 and Nanog can be used as specific markers to detect DPSCs with high multipotent differentiation potential $[13,54,55]$. Studies in hESCs has revealed that the regulatory loop between Oct $3 / 4$, Sox 2 and Nanog genes are uncoupled, allowing the expression of Sox 2 in the absence of Nanog and Oct $3 / 4$; and similarly, expression of Oct $3 / 4$ in the absence of Sox 2 and Nanog. It has been proposed that each factor controls specific cell fate and lineage commitment [56]. Nevertheless, the expressions of these genes are indicative of indefinite stem cell division, with unaffected differentiation potential or the capacity for self-renewal [57]. Our immunostaining and QRT-PCR results indicated, Oct3/4, Nanog, Sox 2 and SSEA-4 markers to be expressed in cells cultured in all media conditions (SF/XF, HS and FBS). This suggests that cells in our study did retain the stemness and multilineage differentiation potential and maintained their self-renewability regardless of serum conditons.

Eventually we investigated the last criteria to define DPSCs as MSCs [50]; cells cultured in FBS, HS or SF/XF differentiation media were assessed for osteogenic, adipogenic and chondrogenic differentiation

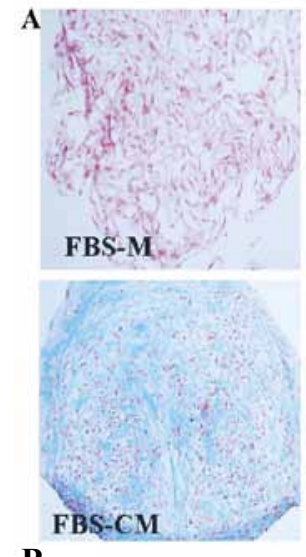

B

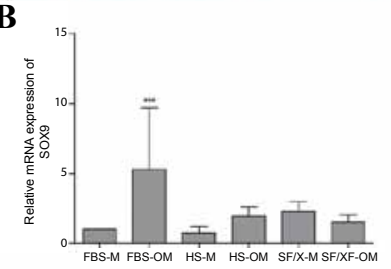

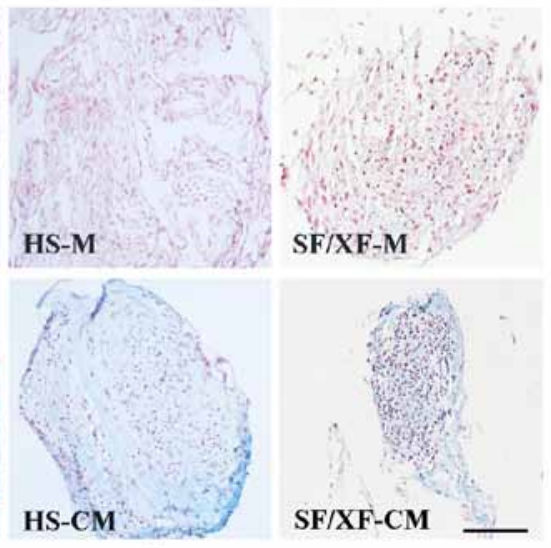

C

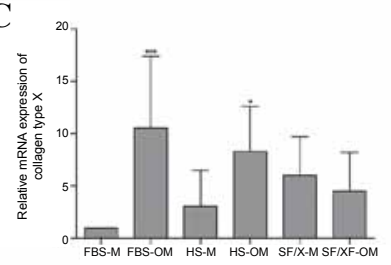

Figure 7: Chondrogenic differentiation analysis for DPSCs cultured in chondrogenic differentiation media in comparison to cells cultured in FBS, HS and SF/XF media. Histological staining by Alcian blue stain of DPSCs micromasses showing chondrogenic differentiation with more proteoglycan content in FBS isolated cells (A) (Scale Bar=100 $\mu \mathrm{m}$ ) and qRT-PCR analysis of chondrogenic differentiation related gene expression for SOX9 (B) and COL10A1 (C). Data represents the mean \pm SD and are normalized to housekeeping gene RPLPO. $\left(n=4,{ }^{*} p<0.05,{ }^{* *} p<0.01{ }^{* * *} p<\right.$ 0.001). (Online version in colour). 
Citation: Khanna-Jain R, Vanhatupa S, Vuorinen A, Sandor GKB, Suuronen R, et al. (2012) Growth and Differentiation of Human Dental Pulp Stem Cells Maintained in Fetal Bovine Serum, Human Serum and Serum-free/Xeno-free Culture Media. J Stem Cell Res Ther 2:126. doi:10.4172/2157-7633.1000126

Page 9 of 11

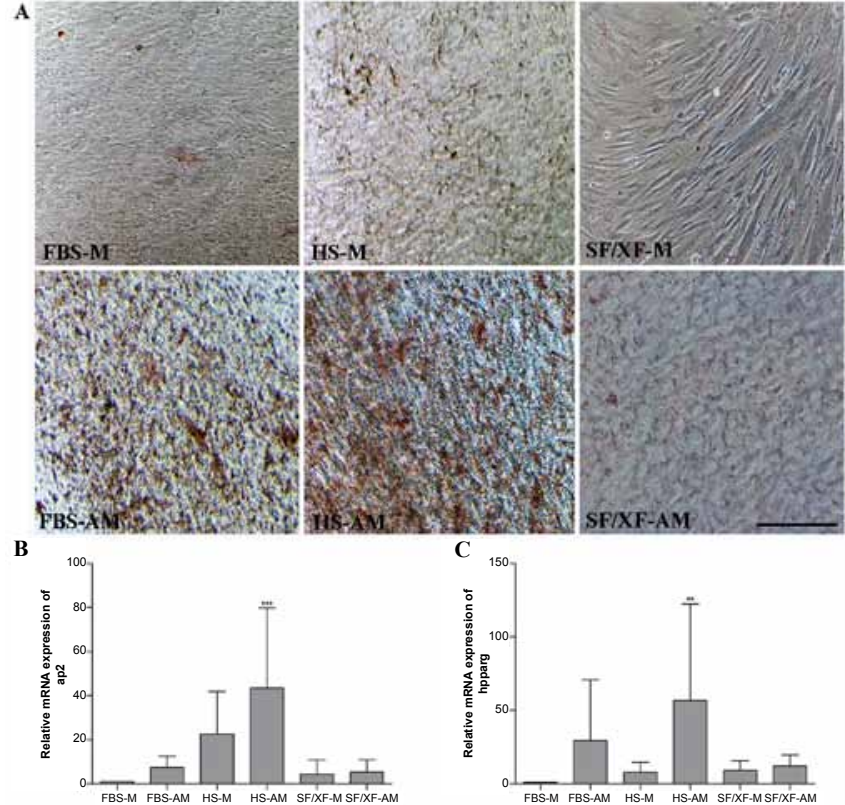

Figure 8: Adipogenic differentiation for DPSCs cultured in FBS-AM, HS$A M$ and SFIXF-AM in comparison to cells cultured in FBS, HS and SFI XF media. Oil O red staining showing lipid accumulation in adipogenically induced cultures $(\mathrm{A})$ (Scale bar $=100 \mu \mathrm{m}$ ) and qRT-PCR analysis of adipogenic differentiation related gene expression for hPPARG (B) and AP2 (C). Data represents the mean $\pm S D$ and are normalized to housekeeping gene RPLPO. $\left(n=4,{ }^{*} p<0.05,{ }^{* *} p<0.01{ }^{* \star *} p<0.001\right)$. (Online version in colour).

potential in vitro. There are several studies reporting the mineralization potential of DPSCs induced by osteogenic medium supplemented with FBS $[11,19,58,59]$, as also shown in our previously published data [46]. However, in our previous study, DPSCs were induced to differentiate osteogenically in FBS medium containing 1a25-dihydroxyvitamin $\mathrm{D}_{3}$ (VD) instead of dexamethasone as an osteogenic inducer. Similarly, here we have shown that mineralized tissue formation was induced by HS-OM supplemented with VD which differentiated DPSCs towards mineral nodule formation. To ensure the osteogenic differentiation, mineralized matrix was stained with alizarin red, which is a specific stain to qualitatively detect calcification in vitro [60]. Additionally, upregulation of OPN (intermediate osteogenic differentiation marker) and OCN (late maker of osteogenic differentiation) expressions were observed which are associated with matrix synthesis and mineralization $[61,62]$ by DPSCs cultivated in FBS-OM and HS-OM at mRNA level. Furthermore, DPSCs cultured in FBS exhibited the capacity to differentiate towards chondrocytes-like cells, as shown in previous studies [20,58]. Here, for the first time we have reported that cells cultured in HS and SF/XF also have the ability to form chondrocyte-like cells. However, in our study SF/XF-OM failed to induce any osteogenic differentiation of DPSCs. As reported in the literature, StemPro ${ }^{\circ} \mathrm{SF} / \mathrm{XF}$ medium supported the multipotent differentiation of AD-MSCs [37], the reason for the discrepancy in our results could be attributed to the absence of unknown growth factors in the SF/XF medium, essential for DPSCs differentiation. However, SF/XF-AM did result in lipid accumulation, but adipogenic differentiation was more pronounced in cells cultured in FBS or HS as observed by oil $\mathrm{O}$ red staining, which revealed intracellular fat droplets [63]. In addition, adipogenic specific markers AP2 and PPARG which are mainly expressed in fat tissue [64] were upregulated in FBS and HS supplemented cultures. Moreover, it is widely known that DPSCs differentiate into adipocytes in FBS adipogenic medium $[9,11]$, but to our knowledge for the first time our investigation has reported adipogenic capacity of DPSCs in HS and SF/ XF supplemented medium.

In summary, our results showed that HS-M supported isolation, expansion, expression of cell surface markers and stemness markers and retained multipotent differentiation capacity of DPSCs similar to FBS-M. Therefore, the use of pooled HS may serve as a safer alternative to FBS for cell therapies. However, the variability in results due to less number of patient samples is the limitation of this study. Nevertheless, these findings are essential for the future clinical studies of DPSCs for their use in stem cell based therapies to bioengineering tissues. Additionally, the composition of SF/XF medium needs to be further optimized for DPSCs culture in terms of cell isolation, expandability and differentiation efficiency to reach clinical applicability.

\section{Acknowledgement}

The authors thank Miia Juntunen, Minna Salomaki, Anna Maija-Honkala, and Sari Kalliokoski for their excellent technical assistance. This work was supported by Tekes-Finnish Funding Agency for Technology and Innovation and Competitive Research Funding of Pirkanmaa hospital district (9L057, 9M058)

\section{References}

1. Jager M, Hernigou P, Zilkens C, Herten M, Li X, et al. (2010) Cell therapy in bone healing disorders. Orthop Rev (Pavia) 2: e20.

2. Friedenstein AJ, Piatetzky S, II, Petrakova KV (1966) Osteogenesis in transplants of bone marrow cells. J Embryol Exp Morphol 16: 381-390.

3. Puissant B, Barreau C, Bourin P, Clavel C, Corre J, et al. (2005) Immunomodulatory effect of human adipose tissue-derived adult stem cells: comparison with bone marrow mesenchymal stem cells. Br J Haematol 129: 118-129.

4. Miller JP, Perry EH, Price TH, Bolan CD Jr, Karanes C, et al. (2008) Recovery and safety profiles of marrow and PBSC donors: experience of the National Marrow Donor Program. Biol Blood Marrow Transplant 14: 29-36.

5. Gimble JM, Katz AJ, Bunnell BA (2007) Adipose-derived stem cells for regenerative medicine. Circ Res 100: 1249-1260.

6. Wei Y, Li Y, Chen C, Stoelzel K, Kaufmann AM, et al. (2011) Human skeletal muscle-derived stem cells retain stem cell properties after expansion in myosphere culture. Exp Cell Res 317: 1016-1027.

7. Carvalho MM, Teixeira FG, Reis RL, Sousa N, Salgado AJ (2011) Mesenchymal stem cells in the umbilical cord: phenotypic characterization, secretome and applications in central nervous system regenerative medicine. Curr Stem Cell Res Ther 6: 221-228.

8. Klemmt PA, Vafaizadeh V, Groner B (2011) The potential of amniotic fluid stem cells for cellular therapy and tissue engineering. Expert Opin Biol Ther 11:1297 1314.

9. Gronthos S, Mankani M, Brahim J, Robey PG, Shi S (2000) Postnatal human dental pulp stem cells (DPSCs) in vitro and in vivo. Proc Natl Acad Sci USA 97: 13625-13630.

10. Huang GT, Gronthos S, Shi S (2009) Mesenchymal stem cells derived from dental tissues vs, those from other sources: their biology and role in regenerative medicine. J Dent Res 88: 792-806.

11. Zhang W, Walboomers XF, Shi S, Fan M, Jansen JA (2006) Multilineage differentiation potential of stem cells derived from human dental pulp afte cryopreservation. Tissue Eng 12: 2813-2823.

12. Huang GT, Yamaza T, Shea LD, Djouad F, Kuhn NZ, et al. (2010) Stem progenitor cell-mediated de novo regeneration of dental pulp with newly deposited continuous layer of dentin in an in vivo model. Tissue Eng Part A 16: $605-615$

13. Huang AH, Snyder BR, Cheng PH, Chan AW (2008) Putative dental pulpderived stem/stromal cells promote proliferation and differentiation of endogenous neural cells in the hippocampus of mice. Stem Cells 26: 26542663. 
Citation: Khanna-Jain R, Vanhatupa S, Vuorinen A, Sandor GKB, Suuronen R, et al. (2012) Growth and Differentiation of Human Dental Pulp Stem Cells Maintained in Fetal Bovine Serum, Human Serum and Serum-free/Xeno-free Culture Media. J Stem Cell Res Ther 2:126. doi:10.4172/2157-7633.1000126

14. Gandia C, Arminan A, Garcia-Verdugo JM, Lledo E, Ruiz A, et al. (2008) Human dental pulp stem cells improve left ventricular function, induce angiogenesis and reduce infarct size in rats with acute myocardial infarction. Stem Cells 26 $638-645$

15. Papaccio G, Graziano A, d'Aquino R, Graziano MF, Pirozzi G, et al. (2006) Long-term cryopreservation of dental pulp stem cells (SBP-DPSCs) and their differentiated osteoblasts: a cell source for tissue repair. J Cell Physiol 208: $319-325$

16. d'Aquino R, Graziano A, Sampaolesi M, Laino G, Pirozzi G, et al. (2007) Human postnatal dental pulp cells co-differentiate into osteoblasts and endotheliocytes: a pivotal synergy leading to adult bone tissue formation. Cell Death Differ 14 1162-1171.

17. Laino G, d'Aquino R, Graziano A, Lanza V, Carinci F, et al. (2005) A new population of human adult dental pulp stem cells: a useful source of living autologous fibrous bone tissue (LAB). J Bone Miner Res 20: 1394-1402.

18. d'Aquino R, De Rosa A, Lanza V, Tirino V, Laino L, et al. (2009) Human mandible bone defect repair by the grafting of dental pulp stem/progenitor cells and collagen sponge biocomplexes. Eur Cell Mater 18: 75-83.

19. Pierdomenico L, Bonsi L, Calvitti M, Rondelli D, Arpinati M, et al. (2005) Multipotent mesenchymal stem cells with immunosuppressive activity can be easily isolated from dental pulp. Transplantation 80: 836-842.

20. Tomic S, Djokic J, Vasilijic S, Vucevic D, Todorovic V, et al. (2011) Immunomodulatory properties of mesenchymal stem cells derived from dental pulp and dental follicle are susceptible to activation by toll-like receptor agonists. Stem Cells Dev 20: 695-708.

21. Heiskanen A, Satomaa T, Tiitinen S, Laitinen A, Mannelin S, et al. (2007) $\mathrm{N}$-glycolylneuraminic acid xenoantigen contamination of human embryonic and mesenchymal stem cells is substantially reversible. Stem Cells 25: 197-202.

22. Shahdadfar A, Fronsdal K, Haug T, Reinholt FP, Brinchmann JE (2005) In vitro expansion of human mesenchymal stem cells: choice of serum is a determinan of cell proliferation, differentiation, gene expression, and transcriptome stability. Stem Cells 23: 1357-1366.

23. Spees JL, Gregory CA, Singh H, Tucker HA, Peister A, et al. (2004) Internalized antigens must be removed to prepare hypoimmunogenic mesenchymal stem cells for cell and gene therapy. Mol Ther 9: 747-756.

24. Dimarakis I, Levicar N (2006) Cell culture medium composition and translational adult bone marrow-derived stem cell research. Stem Cells 24: 1407-1408.

25. Aghayan HR, Arjmand B, Norouzi-Javidan A, Saberi H, Soleimani M, et al. (2011) Clinical grade cultivation of human Schwann cell, by the using of human autologous serum instead of fetal bovine serum and without growth factors. Cell Tissue Bank 13: 281-285.

26. Naveau A, Lataillade JJ, Fournier BP, Couty L, Prat M, et al. (2011) Phenotypic study of human gingival fibroblasts in a medium enriched with platelet lysate. $J$ Periodontol 82: 632-641.

27. Ang LP, Do TP, Thein ZM, Reza HM, Tan XW, et al. (2011) Ex vivo expansion of conjunctival and limbal epithelial cells using cord blood serum-supplemented culture medium. Invest Ophthalmol Vis Sci 52: 6138-6147.

28. Lin HT, Tarng YW, Chen YC, Kao CL, Hsu CJ, et al. (2005) Using human plasma supplemented medium to cultivate human bone marrow-derived mesenchyma stem cell and evaluation of its multiple-lineage potential. Transplant Proc 37 4504-4505.

29. Ichiyanagi T, Anabuki K, Nishijima Y, Ono H (2010) Isolation of mesenchymal stem cells from bone marrow wastes of spinal fusion procedure (TLIF) for low back pain patients and preparation of bone dusts for transplantable autologous bone graft with a serum glue. Biosci Trends 4: 110-118.

30. Aldahmash A, Haack-Sorensen M, Al-Nbaheen M, Harkness L, Abdallah BM et al. (2011) Human Serum is as Efficient as Fetal Bovine Serum in Supporting Proliferation and Differentiation of Human Multipotent Stromal (Mesenchymal) Stem Cells In Vitro and In Vivo. Stem Cell Rev 7: 860-868.

31. Kuznetsov SA, Mankani MH, Robey PG (2000) Effect of serum on human bone marrow stromal cells: ex vivo expansion and in vivo bone formation. Transplantation 70: 1780-1787.

32. Bieback K, Hecker A, Kocaomer A, Lannert H, Schallmoser K, et al. (2009) Human alternatives to fetal bovine serum for the expansion of mesenchymal stromal cells from bone marrow. Stem Cells 27: 2331-2341.
33. Kobayashi T, Watanabe H, Yanagawa T, Tsutsumi S, Kayakabe M, et al. (2005) Motility and growth of human bone-marrow mesenchymal stem cells during ex vivo expansion in autologous serum. J Bone Joint Surg Br 87: 1426-1433.

34. Tateishi K, Ando W, Higuchi C, Hart DA, Hashimoto J, et al. (2008) Comparison of human serum with fetal bovine serum for expansion and differentiation of human synovial MSC: potential feasibility for clinical applications. Cell Transplant 17: 549-557.

35. Lindroos B, Aho KL, Kuokkanen H, Raty S, Huhtala H, et al. (2010) Differentia gene expression in adipose stem cells cultured in allogeneic human serum versus fetal bovine serum. Tissue Eng Part A 16: 2281-2294

36. Chase LG, Lakshmipathy U, Solchaga LA, Rao MS, Vemuri MC (2010) A nove serum-free medium for the expansion of human mesenchymal stem cells. Stem Cell Res Ther 1: 8

37. Lindroos B, Boucher S, Chase L, Kuokkanen H, Huhtala H, et al. (2009) Serumfree, xeno-free culture media maintain the proliferation rate and multipotentiality of adipose stem cells in vitro. Cytotherapy 11: 958-972.

38. Hirata TM, Ishkitiev N, Yaegaki K, Calenic B, Ishikawa H, et al. (2010) Expression of multiple stem cell markers in dental pulp cells cultured in serumfree media. J Endod 36: 1139-1144.

39. Pfaffl MW (2001) A new mathematical model for relative quantification in realtime RT-PCR. Nucleic Acids Res 29: e45.

40. Gronthos S, Brahim J, Li W, Fisher LW, Cherman N, et al. (2002) Stem cell properties of human dental pulp stem cells. J Dent Res 81: 531-535.

41. Laino G, Carinci F, Graziano A, d'Aquino R, Lanza V, et al. (2006) In vitro bone production using stem cells derived from human dental pulp. J Craniofac Surg 17: $511-515$

42. Chadipiralla K, Yochim JM, Bahuleyan B, Huang CY, Garcia-Godoy F, et al (2010) Osteogenic differentiation of stem cells derived from human periodontal ligaments and pulp of human exfoliated deciduous teeth. Cell Tissue Res 340 323-333.

43. d'Aquino R, De Rosa A, Laino G, Caruso F, Guida L, et al. (2009) Human dental pulp stem cells: from biology to clinical applications. J Exp Zool B Mo Dev Evol 312B: 408-415.

44. Mori G, Centonze M, Brunetti G, Ballini A, Oranger A, et al. (2010) Osteogenic properties of human dental pulp stem cells. J Biol Regul Homeost Agents 24 167-175.

45. Karbanova J, Soukup T, Suchanek J, Pytlik R, Corbeil D, et al. (2010) Characterization of Dental Pulp Stem Cells from Impacted Third Molars Cultured in Low Serum-Containing Medium. Cells Tissues Organs 193: 344 365

46. Khanna-Jain R, Vuorinen A, Sandor GK, Suuronen R, Miettinen S (2010) Vitamin $\mathrm{D}(3)$ metabolites induce osteogenic differentiation in human dental pulp and human dental follicle cells. J Steroid Biochem Mol Biol 122: 133-141.

47. Graziano A, d'Aquino R, Laino G, Papaccio G (2008) Dental pulp stem cells: a promising tool for bone regeneration. Stem Cell Rev 4: 21-26.

48. Komoda H, Okura H, Lee CM, Sougawa N, Iwayama T, et al. (2010) Reduction of $\mathrm{N}$-glycolylneuraminic acid xenoantigen on human adipose tissue-derived stromal cells/mesenchymal stem cells leads to safer and more useful cell sources for various stem cell therapies. Tissue Eng Part A 16: 1143-1155.

49. Yilmaz M, Ovali E, Akdogan E, Durmus A, Sonmez M, et al. (2008) Autologous serum is more effective than fetal bovine serum on proliferation of bone marrow derived human mesenchymal stem cells. Saudi Med J 29: 306-309.

50. Dominici M, Le Blanc K, Mueller I, Slaper-Cortenbach I, Marini F, et al. (2006) Minimal criteria for defining multipotent mesenchymal stromal cells. The International Society for Cellular Therapy position statement. Cytotherapy 8 : 315-317.

51. Goodison S, Urquidi V, Tarin D (1999) CD44 cell adhesion molecules. Mol Pathol 52: 189-196.

52. Foreman MA, Smith J, Publicover SJ (2006) Characterisation of serum-induced intracellular $\mathrm{Ca} 2+$ oscillations in primary bone marrow stromal cells. J Cell Physiol 206: 664-671.

53. Shi S, Gronthos S (2003) Perivascular niche of postnatal mesenchymal stem cells in human bone marrow and dental pulp. J Bone Miner Res 18: 696-704.

54. Atari M, Gil-Recio C, Fabregat M, Garcia-Fernandez DA, Barajas M, et al. 
Citation: Khanna-Jain R, Vanhatupa S, Vuorinen A, Sandor GKB, Suuronen R, et al. (2012) Growth and Differentiation of Human Dental Pulp Stem Cells Maintained in Fetal Bovine Serum, Human Serum and Serum-free/Xeno-free Culture Media. J Stem Cell Res Ther 2:126. doi:10.4172/2157-7633.1000126

(2012) Dental Pulp of the Third Molar: A New Source of Pluripotent-like Stem Cells. J Cell Sci [Epub ahead of print]

55. Kawanabe N, Murata S, Fukushima H, Ishihara Y, Yanagita T, et al. (2012) Stage-specific embryonic antigen-4 identifies human dental pulp stem cells. Exp Cell Res 318: 453-463.

56. Wang Z, Oron E, Nelson B, Razis S, Ivanova N (2012) Distinct lineage specification roles for NANOG, OCT4, and SOX2 in human embryonic stem cells. Cell Stem Cell 10: 440-454.

57. Kerkis I, Kerkis A, Dozortsev D, Stukart-Parsons GC, Gomes Massironi SM, et al. (2006) Isolation and characterization of a population of immature dental pulp stem cells expressing OCT-4 and other embryonic stem cell markers. Cells Tissues Organs 184: 105-116.

58. Alge DL, Zhou D, Adams LL, Wyss BK, Shadday MD, et al. (2010) Donormatched comparison of dental pulp stem cells and bone marrow-derived mesenchymal stem cells in a rat model. J Tissue Eng Regen Med 4: 73-81.

59. Lindroos B, Maenpaa K, Ylikomi T, Oja H, Suuronen R, et al. (2008) Characterisation of human dental stem cells and buccal mucosa fibroblasts. Biochem Biophys Res Commun 368: 329-335.
60. Lazcano O, Li CY, Pierre RV, O'Duffy JD, Beissner RS, et al. (1993) Clinical utility of the alizarin red $S$ stain on permanent preparations to detect calciumcontaining compounds in synovial fluid. Am J Clin Pathol 99: 90-96.

61. Viereck V, Siggelkow H, Tauber S, Raddatz D, Schutze N, et al. (2002) Differential regulation of Cbfa1/Runx2 and osteocalcin gene expression by vitamin-D3, dexamethasone, and local growth factors in primary human osteoblasts. J Cell Biochem 86: 348-356.

62. McKee MD, Nanci A (1996) Osteopontin at mineralized tissue interfaces in bone, teeth, and osseointegrated implants: ultrastructural distribution and implications for mineralized tissue formation, turnover, and repair. Microsc Res Tech 33: 141-164

63. Hopkins PM, Kermeen F, Duhig E, Fletcher L, Gradwell J, et al. (2010) Oil red $O$ stain of alveolar macrophages is an effective screening test for gastroesophageal reflux disease in lung transplant recipients. J Heart Lung Transplant 29: 859-864.

64. Farmer SR (2006) Transcriptional control of adipocyte formation. Cell Metab 4: $263-273$. 